severe thrombocytopenia $(<50 \mathrm{~K} / \mu \mathrm{l})$ was present in $28.7 \%$ of patients. Finally, $25.8 \%$ of patients presented with pancytopenia.

In $72.3 \%$ of patients, bone marrow interpretation, along with clinical and laboratory findings, lead to a conclusive diagnosis. The most common final diagnoses were disease activity $(24.8 \%)$ and drug-associated toxicity (28.7\%). The agreement between the initial diagnostic impression and the conclusion after BMA was performed was $45.5 \%$.

We analyzed factors associated with the most common etiologies (table 1). Regarding BMA findings, when cytopenias were secondary to disease activity, it was more frequent for the bone marrow to be hypercellular (56 vs $23 \%, \mathrm{p}=0.006$ ) and to have increased megakaryocytes $(40$ vs $17.4 \%$, $\mathrm{p}=0.048$ ). Conversely, granulocytic dysplasia was less common in this group of patients $(17.4 \%$ vs $54.3 \%, \mathrm{p}=0.036)$.

After multivariate analysis, a neutrophil count $<1000$ cells $/ \mu$ 1 was a protective factor for disease activity (OR 0.021 ; 95\% CI $0.001-0.428, \mathrm{p} 0.012$ ). On the other hand, a history of renal activity (OR 4.3; 95\% CI 1.3-14.2, p=0.024) and neutrophils $<1000$ cells/ $\mu$ l (OR 4.05; 95\% CI 1.15-14.19, $\mathrm{p}=0.029$ ) were found to be independent risk factors for myelotoxicity.

Conclusions The most frequent diagnoses of SLE patients presenting with cytopenias were disease activity and drug-associated bone marrow toxicity. There are clinical characteristics and laboratory findings that may guide the diagnostic approach and thus, choose the most appropriate therapeutic intervention. BMA and biopsy play a key role in complementing the study of cytopenias in SLE patients, allowing for a complete evaluation of the particular context of each patient.

Funding Source(s): None

\section{LEVERAGING A COMMUNITY-ACADEMIC PARTNERSHIP TO INCREASE LUPUS AWARENESS IN VULNERABLE COMMUNITIES}

'Karen Mancera-Cuevas, 'Rosalind Ramsey-Goldman*, 'Joan S Chmiel, 'Daniel L Erickson, ${ }^{1}$ Anh H Chung, ${ }^{2}$ Patricia Canessa, ${ }^{2}$ Candace H Feldman. ${ }^{4}$ Courtnie R Phillip. ${ }^{1}$ Northwestern University, Feinberg School of Medicine; ${ }^{2}$ Illinois Public Health Association; ${ }^{3}$ Division of Rheumatology, Immunology and Allergy, Brigham and Women's Hospital; ${ }^{4}$ Brigham Women's Hospital

\subsection{6/lupus-2019-Ism.143}

Background The Popular Opinion Leader (POL) model was developed by the Centers of Disease Control to train community leaders to increase awareness in their social networks about health-related issues that disproportionately affect vulnerable populations. We established an academic-community partnership in Chicago and Boston and used a POL model to increase knowledge about lupus and to promote early careseeking behaviors among African American individuals. With the knowledge that where a person lives directly influences his/her health, one of our goals was to understand the sociodemographic characteristics of the Chicago communities where the POLs disseminated lupus-related information.

Methods Ten POLs were identified and participated in four two-hour session educational training program. All POLs were female, the mean age was 59\% and 100\% were African American. Over the course of 6 months, the POLs tracked their encounters throughout their social networks by recording addresses of venues where educational information was disseminated and the number of individuals contacted. Data were

\begin{tabular}{lllll}
\multicolumn{4}{l}{ Abstract 143 Table 1} & \multicolumn{4}{l}{ Chicago sociodemographic factors } \\
\hline Community-Level Data & $\begin{array}{l}\text { Washington } \\
\text { Heights }\end{array}$ & $\begin{array}{l}\text { Morgan } \\
\text { Park }\end{array}$ & Englewood & Roseland \\
\hline $\begin{array}{l}\text { Racial Composition } \\
\% \text { African American }\end{array}$ & $95.8 \%$ & $54.6 \%$ & $95 \%$ & $96.1 \%$ \\
$\begin{array}{l}\text { Clinical } \\
\begin{array}{l}\text { No health insurance } \\
\text { Economic }\end{array}\end{array}$ & $10.5 \%$ & $8.4 \%$ & $17.2 \%$ & $12.4 \%$ \\
$\begin{array}{l}\text { Individual Poverty * } \\
\text { Education }\end{array}$ & $18.6 \%$ & $18.5 \%$ & $30.8 \%$ & $27.2 \%$ \\
$\begin{array}{l}\text { Not a high school } \\
\text { graduate }\end{array}$ & $10.1 \%$ & $10.7 \%$ & $19.7 \%$ & $13.5 \%$ \\
\hline
\end{tabular}

* Individual poverty is classified as percent below Federal Poverty Level (U.S Census; American Community Survey 2010-2015).

entered into the Geographic Information System to evaluate the reach of their networks. We utilized the Healthy Chicago Database to describe the sociodemographic factors and some of the health resources of the Chicago neighborhoods identified by the POLs social networks.

Results The 10 POLs social networks were concentrated in four selected communities (Washington Heights, Morgan Park, Englewood and Roseland). These neighborhoods are located on the Southside of Chicago where health, educational, and financial resources are limited. All four communities were predominantly African-American, range 54.6\%-96.1\%. Individuals living in these neighborhoods with no health insurance ranged from 8.4\%-17.2\%, in Morgan Park and Englewood, respectively. Individual poverty was highest in Englewood $(30.8 \%)$ and Roseland $(27.2 \%)$ compared with approximately $18 \%$ in the other two neighborhoods. The percentage of individuals who did not complete high school was highest in Englewood (19.7\%) and Englewood (13.5\%) compared with approximately $10 \%$ in the other two areas.

Conclusions Engagement of local community members through POL conversations tapped into neighborhoods that demonstrated concerning sociodemographic features such as individual poverty, lack of health insurance, and lack of education through high school. Since the POLs had strong social networks prior to recruitment, they selected these communities to facilitate dissemination of lupus awareness education where resources may be limited. This illustrates the importance of POL engagement with community stakeholders who can use this information to work towards reducing health disparities in lupus in communities with limited resources.

Funding Source(s): DHHS, Office of Minority Health

\section{YOUNG SLE PATIENTS HAVE HIGHER CORONARY ARTERY CALCIUM SCORES COMPARED WITH POPULATION CONTROLS}

${ }^{1}$ Yevgeniya Gartshteyn*, ${ }^{1}$ Genna Braverman, ${ }^{2}$ Sharan Mahtani, 'Laura Geraldino-Pardilla, 'Sabahat Bokhari, ${ }^{3}$ Anca D Askanase. ${ }^{1}$ Columbia University Medical Center; ${ }^{2}$ University of Edinburgh Medical School; ${ }^{3}$ Columbia University

\subsection{6/lupus-2019-Ism.144}

Background Cardiovascular disease (CVD) is a leading cause of death in systemic lupus erythematosus (SLE). The 